Article

\title{
Object-Based Analysis Using Unmanned Aerial Vehicles (UAVs) for Site-Specific Landslide Assessment
}

\author{
Efstratios Karantanellis ${ }^{1, *(\mathbb{D}}$, Vassilis Marinos ${ }^{1}$ (D), Emmanuel Vassilakis ${ }^{2}$ (D) and \\ Basile Christaras ${ }^{1}$ \\ 1 Laboratory of Engineering Geology and Hydrogeology, Department of Geology, Aristotle University of \\ Thessaloniki, 54124 Thessaloniki, Greece; marinosv@geo.auth.gr (V.M.); christar@geo.auth.gr (B.C.) \\ 2 Remote Sensing Laboratory, Department of Geology and Geoenvironment, National and Kapodistrian \\ University of Athens, 15784 Zografou, Greece; evasilak@geol.uoa.gr \\ * Correspondence: karantan@geo.auth.gr
}

Received: 23 April 2020; Accepted: 23 May 2020; Published: 27 May 2020

\begin{abstract}
The increased development of computer vision technology combined with the increased availability of innovative platforms with ultra-high-resolution sensors, has generated new opportunities and fields for investigation in the engineering geology domain in general and landslide identification and characterization in particular. During the last decade, the so-called Unmanned Aerial Vehicles (UAVs) have been evaluated for diverse applications such as 3D terrain analysis, slope stability, mass movement hazard and risk management. Their advantages of detailed data acquisition at a low cost and effective performance identifies them as leading platforms for site-specific 3D modelling. In this study, the proposed methodology has been developed based on Object-Based Image Analysis (OBIA) and fusion of multivariate data resulted from UAV photogrammetry processing in order to take full advantage of the produced data. Two landslide case studies within the territory of Greece, with different geological and geomorphological characteristics, have been investigated in order to assess the developed landslide detection and characterization algorithm performance in distinct scenarios. The methodology outputs demonstrate the potential for an accurate characterization of individual landslide objects within this natural process based on ultra high-resolution data from close range photogrammetry and OBIA techniques for landslide conceptualization. This proposed study shows that UAV-based landslide modelling on the specific case sites provides a detailed characterization of local scale events in an automated sense with high adaptability on the specific case site.
\end{abstract}

Keywords: landslide assessment; UAV photogrammetry; remote sensing; object-based image analysis (OBIA); mass movements; surface deformation; SfM processing

\section{Introduction}

Natural hazards pose a major threat in multiple regions of the world and usually cause crucial economic dislocation, environmental impacts and fatal injuries. Landslides represent one of the most destructive natural hazards, and often cause substantial human and infrastructure losses which form significant obstacles to the sustainable development of a healthy society [1]. Landslides and rockfalls constitute one of the most widespread geo-hazards which take place every year in Greece and they have terrible consequences for the overall sustainability. In general, mass land movements are complex systems, which can be described as the movement of different kinds of sources such as rocks, soil or debris down a slope, and they are expected to occur most often under similar circumstances to those that have led to past slope failures. In most of the cases, those failures are linked as indirect post-events 
after heavy rainfall [2] or seismic events [3] and the majority cause considerable losses. These mass movements are indeed favored along pre-existing instabilities and their timely identification is of primary importance. The tremendous effects of landslides have serious impacts on the anthropogenic environment [4] and most of the times the event is abrupt with no warning sign of failure and inability to collect post-event information due to site inaccessibility [5]. In the past, several multi-organization collaborative research projects have been carried out for landslide hazard and risk management such as "Safeland" project. Its main task was to develop informative quantitative risk management strategies for landslides across Europe at the regional and national scales, but a few studies have been done on a local scale [6]. In order to enhance landslide and rockfall capacity and preparedness and produce detailed landslide inventories in a cost and time effective manner, detection and mapping of those events using "state-of-the-art" remote sensing products has been proved to be a promising approach to provide susceptibility, hazard and risk maps [7]. The main task of a landslide inventory is to produce detailed maps that show the landslides' exact location, extent and movement magnitude [8,9]. The conventional engineering geological mapping, which is a significant component of site investigation of a particular landslide or rockfall site, is primarily based on ground survey, which includes field mapping from experienced experts. Recently, there has been increasing interest in developing automatic and accurate procedures for landslide and rockfall segmentation and characterization into meaningful hazard entities, aiming at replacing subjective conventional, expensive manual procedures for delineating and assessing those catastrophic events in site specific scales.

\section{Remote Sensing Evolution in Landslide Monitoring}

In the last decades, remote sensing (RS) techniques and geographical information systems (GIS) have undergone rapid development in among other areas, regarding the investigation in the field of landslide management [10]. The combination of efficient and precise data acquisition and time-effective, highly accurate analysis of that data, have made the RS and GIS applications integral parts of landslide investigations [11,12]. The extended need for automated unbiased landslide recognition procedures has led to the development of image processing techniques, which can be divided into pixel-based approaches including unsupervised [13] and supervised classification [14] and lately to object-based techniques $[15,16]$, object-based image analysis (OBIA) or geographic object based image analysis (GeOBIA) which have been used for over two decades as a framework for feature extraction, especially based on the latest advances with very high spatial resolution imagery. In addition, object-based classification approaches have been proved to result in higher accuracy while simultaneously, they aggregate pixels into a network of homogeneous objects corresponding to realistic surface patterns compared with traditional pixel-based methods [17]. A large number of researchers have pointed out the superiority of object-based procedures over the traditional pixel-based ones [18-21]. The OBIA approach consists of two distinct phases: a segmentation and a classification procedure. According to the literature, it is advisable that image objects produced by a segmentation process should be linked with a relation to the geographic objects of interest which in the current case are landslide features [22]. Thus, segmentation constitutes a crucial step towards obtaining optimal classification results [23]. The best-fit values of these variables for a specific case site can be estimated by semi-automatic methods such as the estimation scale parameter (ESP) [24], or optimum scale parameter selector (OSPS) [25], or through trial and error methods [7,26,27]. Although different classification algorithms have been evaluated for landslide detection such as random forests (RF) [28], genetic algorithms [26], mathematical morphology [29], support vector machines (SVM) [30], and artificial neural networks (ANN) [31], these methods all suffer from limitations regarding site-specific landslide assessment. Additionally, most studies lack valuable semantic information on landslide- specific elements and how they react with the surrounding environment, natural and man-made objects [32]. Furthermore, pixel-based techniques rely solely on the spectral signal of individual pixels which constitutes a disadvantage concerning the amount of information available today. The development of OBIA has been of particular significance to ultra-high-resolution land cover mapping [33,34], especially for site-specific scales [35]. As so, it is 
crucial to investigate their distinct elements and their respective behavior in terms of computer vision sense aiming to neglect as much as possible the human factor which leads to subjective results. It should be mentioned that specialists understand a landslide case site as a scene of discrete entities such as the landslide source and deposition area, non-affected regions, multiple assets such as vegetation, road networks and other scene elements characterized by specific properties such as colour, shape and spatial patterns.

Manned aircraft can sometimes offer high spatial resolution data for landslide study purposes, but those systems have some serious drawbacks such as their operating costs for flying over large areas. Lately, close-range remote sensing technology such as unmanned aerial vehicle (UAV) photogrammetry and terrestrial laser scanning (TLS) surveys have been extensively applied in the geoscience domain due to their effectiveness in rapidly collecting precise and accurate terrain morphology data [36]. UAVs or remotely piloted aircraft systems (RPAS, commercially named drones) have shown tremendous growth in the field of landslide mapping due to their effectiveness and efficiency in gathering valuable data throughout the affected areas $[37,38]$. The term UAV, which is more common in the literature, covers all vehicles flying in the air with no person on board with the capability of controlling the aircraft [39]. The main principle is that a UAV takes aerial images, incorporated with spatial data based on global navigation satellite system (GNSS) and an inertial measurement unit (IMU), over an area to produce a very high resolution 3D point cloud [40]. Advantages such as the repetitive measurement capability and low cost, while still being able to provide very high spatial data resolution in comparison to satellite and aircraft data capture systems, are positioning UAVs in a very promising data acquisition platform for multidimensional purposes [41]. Thus, in recent times, the use of UAVs in landslide monitoring has shown an extreme growth [42] and the future seems promising in terms of sensor capability. Those platforms are able to fly and collect datasets over disaster areas where human access for in situ studies is impossible [43]. Most of the studies are focusing in the delineation of the affected area from UAV orthophotos and the classification of the hazardous area based on a number of factors [44]. On the contrary, some researchers such as [45] choose to follow a more topographical approach by using as main input a high-resolution digital surface model (DSM) of the landslide area in order to identify the affected area based on multitemporal topographic factors such as slope and aspect. Geological formations such as fault and rupture zones have been identified in [46] by applying feature detection with a UAV platform immediately after the event. Lately [47] has reported the execution of several flights using a micro-UAV to investigate the DSM generation in the Super-Sauze landslide in France which cost several human lives. The latter provided a detailed analysis of the Super-Sauze landslide kinematics which can serve as a basis for further protection measures. Moreover, ref. [48] used a small fixed-wing UAV mounted with a consumer camera to collect data in order to produce detailed DSMs to monitor and provide an assessment of gully erosion in North Africa. In addition, ref. [49] displayed the applicability of UAV platforms in landslide monitoring by incorporating machine learning and computer vision techniques in 3D reconstruction of the Oso mudslide in Washington for deeper understanding of mass movement mechanism. Also, ref. [50] described several flights over a large area to delineate landslide displacements with a fixed-wing platform. In contrary, light detection and ranging (LiDaR) sensors for landslide studies are dealing with the characterization of the affected area and they are characterized by the advantage of mitigating the influence of vegetation. In a number of landslide cases, due to the passing of time the vegetation has restructured well and failure characteristics such as scarp and/or the landslide body are not visible clear from a passive sensor [51]. Therefore, LiDaR sensors constitute valuable tools in monitoring and detecting unstable vegetated slopes, but contrary to UAVs, they have higher costs in terms of operational needs. A great example is presented in [52] where both active and passive sensors are compared and evaluated in extraction of geomorphological and geological characteristics with high accuracy rates in a case study occurred in Vorarlberg (Austria). 
In the current study, the proposed method illustrates the effectiveness and efficiency of UAV platforms to acquire cost-efficient data from difficult environments and complex surface topographies. The methodology is divided into five main working phases. The first phase includes designing and execution of an optimal UAV flight planning to collect accurate 3D data depending on the local morphology of the case site. Structure from motion ( $\mathrm{SfM}$ ) photogrammetry in addition to high accuracy RTK-GNSS ground control point establishment, is used to provide detailed 3D point clouds describing the surface morphology of the landslide and rockfall events. During the second phase, pre-processing and raw data preparation steps such as point cloud filtering and elimination of ambiguities has been executed. At the next phase, an image segmentation algorithm followed by detailed classification has been processed using the UAV orthophoto and DSM derivatives. The main task was focused on identifying the specific landslide elements by using an object-based concept. A sequence of image-based processes was applied, including multi-scale object segmentation, spectral, morphometric and contextual information extraction aiming to identify characteristic mass movement features. The following phase was set up for object characterization in meaningful and homogeneous landslide classes (e.g., scarp, deposition or tension fissures and cracks) which are spatially connected by introducing contextual information. Thus, the evaluation of object-based methods on UAV data for landslide mapping has been investigated in the Greek territory, which includes diverse climatic and terrain conditions. The present work aims to demonstrate the applicability of UAV sensors as a cost-effective and efficient solution for semi-automated semantic labeling as initial mass movement assessment in harsh environments during emergency situations. In the present study, the structure from motion-multi-view stereo (SfM-MVS) algorithm was applied to generate detailed dense 3D point clouds, digital surface models (DSMs), and orthophotos of the respective areas. The latter will be used as primary datasets for the object-based landslide detection and characterization. The workflow is described as follows: (1) image selection, (2) sparse point cloud reconstruction based on SfM, (3) dense point cloud reconstruction based on multi view-stereo (MVS) and (4) orthoimage and DSM generation [53]. It has to be highlighted that the details of SfM and the principles of close-range photogrammetry will not be covered in any great extent in this work as the main focus is the application of the platform in slope characterization using computer vision techniques.

\section{Data Collection}

\subsection{Study Areas}

Two landslide-prone areas in the Greek territory with different geological and geomorphological characteristics were selected and investigated as test sites for the development of the presented object-based mapping approach. The two study areas: (a) Red Beach on the island of Santorini and (b) Proussos in Evritania prefecture are characterized by great land use/cover diversity, geo-environmental settings, landslide mechanisms and data acquisition parameterization. The workflow is comprised of four main phases: (a) pre field work and on-site and data collection; (b) primary data preparation; (c) landslide object recognition and characterization and (d) data presentation and visualization. Each phase is explained in detail in the subsequent sections.

The island of Santorini is located in the south region of the Cyclades Archipelago in the Mediterranean Sea (Figure 1). It is formed completely from volcanic material of dacitic and andesitic composition formed during the Pre-Minoan eruption era [54]. It should be mentioned that Santorini has a unique morphology with very steep cliffs susceptible to erosion processes [55]. As a result, many regions on the west part of the island are prone to landslide and rockfall events. The area under investigation was named as "Red Beach" due to the oxidation of the lava composition which provides the characteristic red colour of the scoria formation. It is situated at the southeastern part of the active volcanic caldera in "Akrotiri" and the area extends for about 1.5 ha and has very high touristic activity throughout the season. The landscape is very steep, composed of the half remaining part of an old volcanic cone, with the slopes generally dipping up to $80^{\circ}$ and up to $40 \mathrm{~m}$ to $45 \mathrm{~m}$ in height. The 
length of the beach is approximately $300 \mathrm{~m}$ and its width ranges between $4-10 \mathrm{~m}$ and it is strongly affected by seasonal coastline displacement. Furthermore, geomaterial of Red Beach is allocated as medium to well cemented scoria and compact lavas in the lower parts. In detail, it is formed from coarse grained medium cemented volcanic breccia and thin grained well cemented volcanic breccia. The latter presents particularly low tensile strength with large open tension fissures and cracks along the wide area. Moreover, discontinuities trending N-S and NE-SW are present in the area normally in the slope direction, after recent tectonic activity [56].

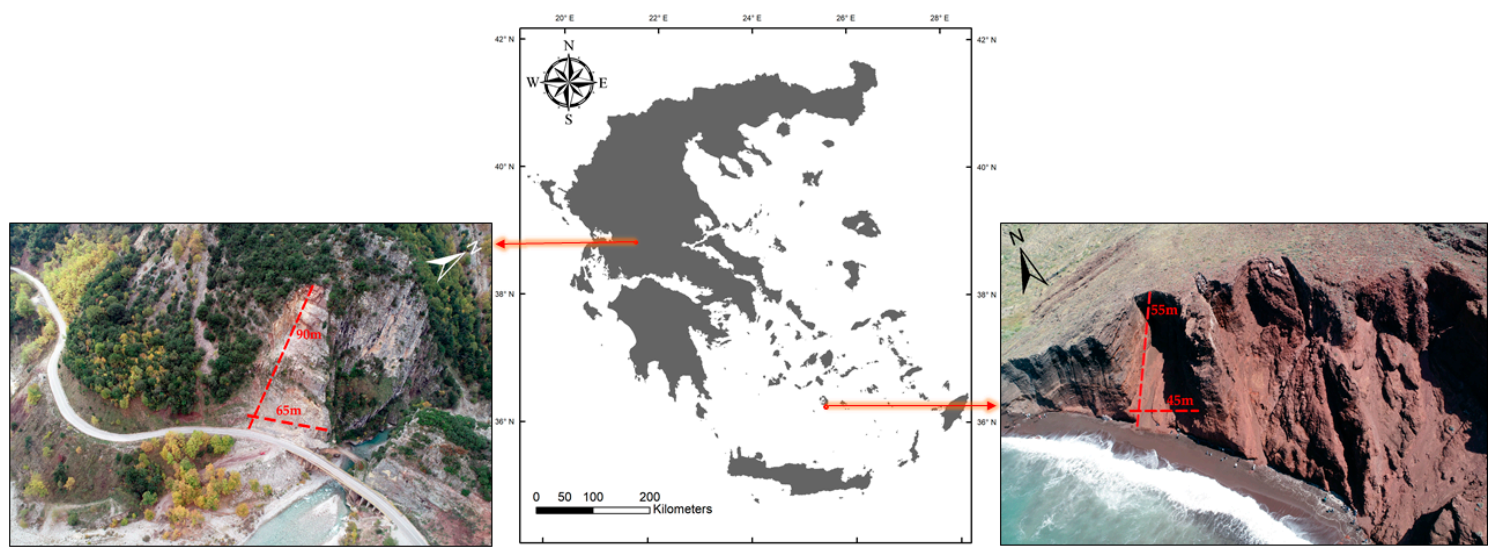

Figure 1. Location of Red Beach case site, Santorini and Proussos case site, Evritania, Greece.

On the other hand, the Proussos site is located in Evritania, which is a mountainous prefecture located on the Greek mainland. The region is considered to belong to the Pindos geotectonic unit and is composed mainly of limestones, flysch and Quaternary deposits. Thin-bedded gray limestone formations are dominant in the area under investigation, with high structural complexity due to intense orogenetic folding and low strength along its discontinuities. Due to intense morphological relief and complex rock mass coupled with extreme climatic conditions, Evritania prefecture has been severely affected by mass movements. Such an example is the test site that is located in the Dipotama area next to the "Balta" bridge. The site is situated across the unique road network leading to one of the most visited and famous monasteries in the territory of Evritania prefecture, in central Greece. The elevation difference of the slope from the top to the toe of the slide is nearly $90 \mathrm{~m}$. The hillslope is approximately $70^{\circ}$ steep, facing North-East (NE) and located at $780 \mathrm{~m}$ absolute elevation. At the test site, several complex mass movements and rockfalls events took place in thin-bedded limestone in the last decade with partial to complete destruction of the road network which results in partial isolation of the Proussos Monastery. Those events have been identified during February-May and their dimensions fluctuate from individual rockslides to massive falls of several hundred cubic meters in volume. The consecutive failures on Proussos' road network have been caused largely by the creation of deep excavations as well as erosion at the toe of the slope due to a river crossing underneath, which in the current case study is not supported by any kind of vegetation or special protective construction works (Figure 2). 

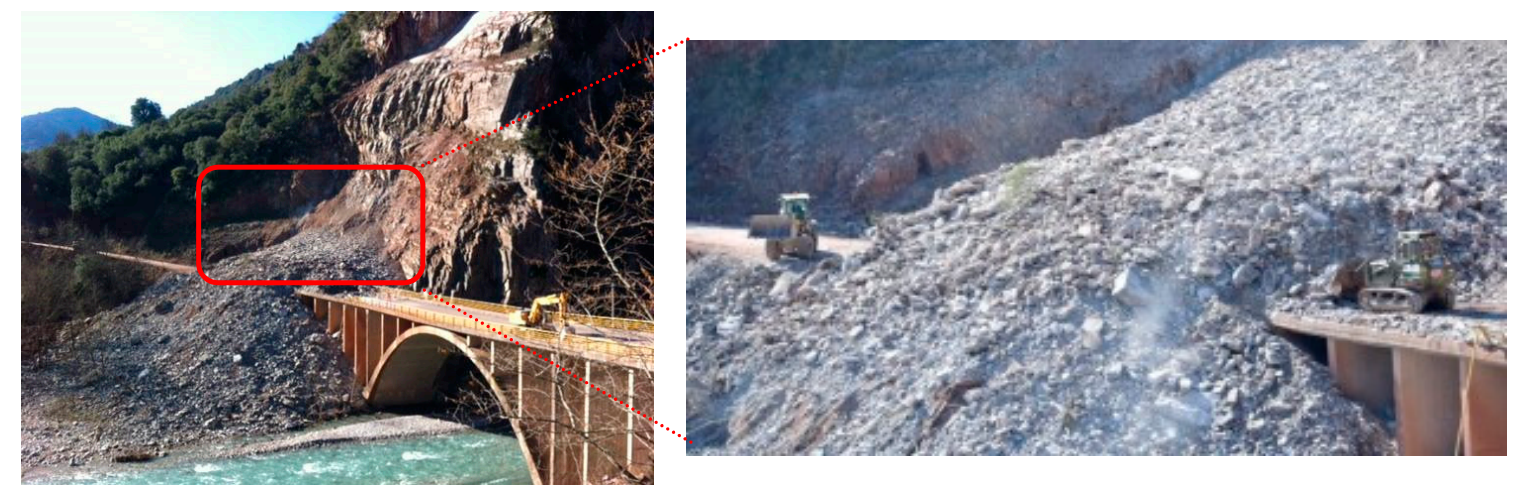

Figure 2. Archival photos from previous mass movement failures at the Proussos site (source: https://www.evritanika.gr).

\subsection{Data Planning and Collection}

The general workflow of the UAV-based image acquisition follows a concrete structure: (a) pre-field work planning, (b) on-site data collection, and (c) post-processing [57]. The pre-field work stage involves an extensive background and literature review of the area in combination with remote assessment of the area under investigation via satellite imagery and web-based applications. Field measurements include production of engineering geological observations (strikes and dips), in-situ tests, interpretative diagrams and a hand-drawn schematic map of the study area. Moreover, the data collection stage has been conducted by using a commercial mini-UAV quadrotor platform (Phantom 4 Pro V2.0, DJI, Technology Co., Ltd. (Shenzhen, China)) equipped with a stabilized built-in camera (1" CMOS-20 megapixel) for capturing and collecting images. The latter were utilized for the generation of the 3D model and the respective DSMs and ortho-photomosaics of Red Beach and Proussos. The abovementioned platform is a flight-capable device that can be launched manually or in a pre-programmed manner to a given area under predefined safety regulations. It uses an onboard GPS/GLONASS navigation system and has been chosen due to its low cost and relatively easy operation on site. The aircraft was programmed to follow a predefined flight path composed from cross-stripes in order to have full coverage of the study areas consisting of steep slopes. The UAV procedure for data collection was initialized firstly, by hovering at a predefined height and position while the camera angle has been adjusted at the first configuration of $60^{\circ}$ using the camera mount and in a later stage in an alternative configuration of $80^{\circ}$ for completing the data collection (Figure 3). In addition, black and white paper signs $(15 \mathrm{~cm} \times 15 \mathrm{~cm})$ have been distributed around the area and used as targets for ground control points (GCPs) to create an arbitrary coordinate system. The latter was performed within the photogrammetric workflow, based on manual identification on the images and surveyed during the field work by measuring accurate coordinates and elevation with RTK-GNSS equipment. During the 3D model production, a small number of GCPs were marked on the images in the processing step to correctly calibrate the resulted model and ensure high spatial quality. The campaigns' quality details are presented in Table 1 with the respective ground sampling distance (GSD) and the respective root mean square error (RMSE) as outlined from the flight campaigns. The computed RMSE was less than a single pixel for the areas under investigation, which was considered satisfactory taking into account the rough terrain and harsh environment.

The magnitude of the Red Beach declivity has been estimated at $300 \mathrm{~m}$ in length and $50 \mathrm{~m}$ in height. It features high inaccessibility and a dangerous environment for humans due to the consecutive failure events. Thus, the latter requires methodical mass movement management by using classical and up-to-date surveying methods to provide holistic assessment. To achieve the best available coverage of the area but at the same time keep the spatial resolution to a high standard (submeter) the flights were performed with a constant predefined flight path with $75 \%$ of sidelap and $80 \%$ frontlap. Approximately, 180 images from a constant flight attitude of $90 \mathrm{~m}$ above ground have been collected following the 
surface topography. In order to preserve optimal matching on the scene, tie points had to be visible in at least six images. GCPs were distributed along the accessible regions of the site. At each acquisition time, $1 / 3$ of the GCPs have been used as points to verify the model error propagation. Furthermore, to derive the final 2D and 3D products, any inconvenient noise due to moving objects (people on the beach) and shadows from the sun angle during the acquisition time have been removed.
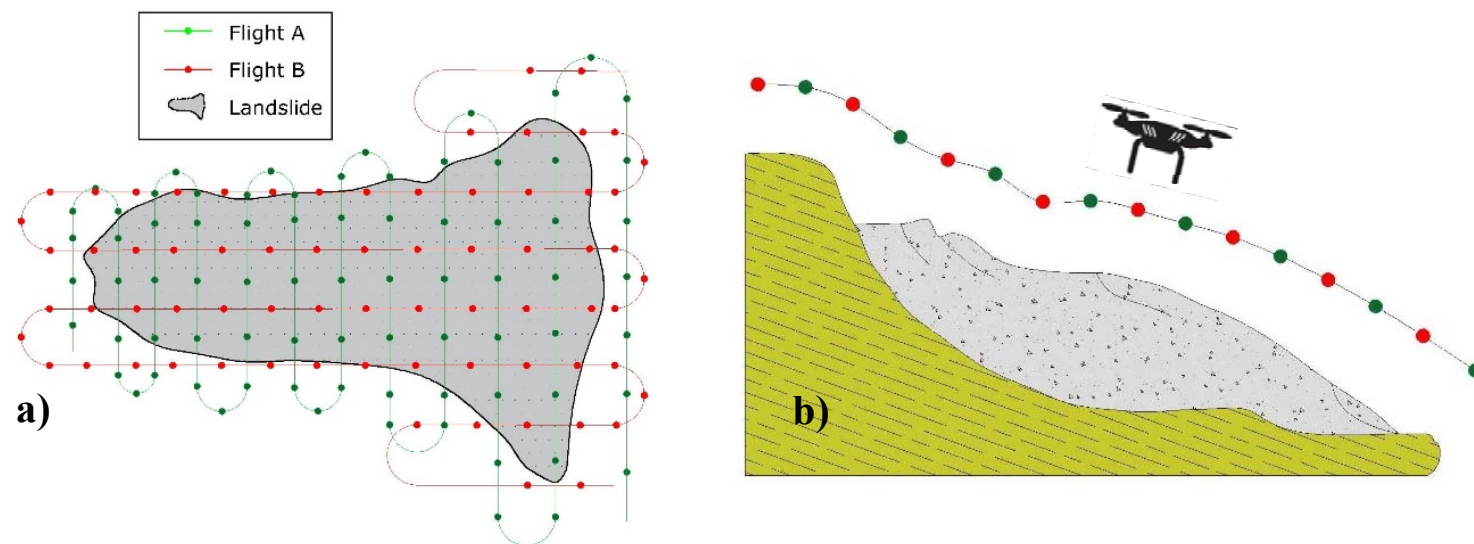

Figure 3. Schematic representation of proposed Unmanned Aerial Vehicles (UAV) flight path for optimal area coverage, (a) plan view and (b) cross section.

Table 1. Acquisition parameters for unmanned aerial vehicles (UAV) flight planning.

\begin{tabular}{ccc}
\hline & Mission Specifications & \\
\hline Parameters & Proussos & Red Beach \\
Number of images & 112 & 180 \\
Flying altitude $(\mathrm{m})$ & 60 & 90 \\
Sidelap-Frontlap & $75 \%-80 \%$ & $75 \%-80 \%$ \\
Ground Resolution $(\mathrm{m})$ & 0.3 & 0.5 \\
Coverage area $\left(\mathrm{km}^{2}\right)$ & 0.132 & 0.143 \\
Number of tie points & 832,147 & $1,776,246$ \\
Overall error in XY $(\mathrm{m})$ & 0.1 & 0.2 \\
Overall error in Z $(\mathrm{m})$ & 0.23 & 0.4 \\
Orthomosaic resolution $(\mathrm{m})$ & 0.5 & 0.5 \\
Digital surface model resolution $(\mathrm{m})$ & 0.5 & 0.5 \\
\hline
\end{tabular}

Following the acquisition concept, at Proussos survey, 112 images have been collected from a constant flight attitude of $60 \mathrm{~m}$ above ground with careful attention to keep the frontlap at $75 \%$ and sidelap in $80 \%$ to guarantee optimal configurations for tie point matching and camera alignment. Following the predefined configuration for optimal scene representation, the landslide scene's tie points were chosen to fulfil the condition to be visible at least in six images. Later, both datasets have been processed using Pix4D S.A. (Lausanne, Switzerland) [58], a commercial structure from motion (SfM) photogrammetric software to produce the DSM, the orthophoto and the 3D point cloud and mesh model of the area under investigation. The SfM procedure produced a dense point cloud constructed from up to 20 million points and the resulting accuracy was $0.5 \mathrm{~m}$ for Proussos. For Red Beach, the dense point cloud included more than 35 million points and the resulting accuracy was also $0.5 \mathrm{~m}$.

\section{Object-Based Image Analysis (OBIA) Methodology}

The stages applied in this study for "intelligent" site-specific landslide assessment based on UAV and object-based approach were composed of four distinct working steps (Figure 4). Accordingly, data collection and model preparation are applied at the initial phase, followed by a SfM-MVS procedure to generate the 3D dense pointcloud which serves as the basis for the orthophoto and DSM derivatives. 
The third phase includes the main working stage of data processing in OBIA and the final phase visualization of the results. In this part, information about the OBIA procedure implemented for landslide detection and classification is given and evaluation about the accuracy of the assessment methods is presented in detail. The reference inventories for the case sites are mostly based on field work supplemented by visual interpretation of aerial photographs, orthoimages and satellite imagery.

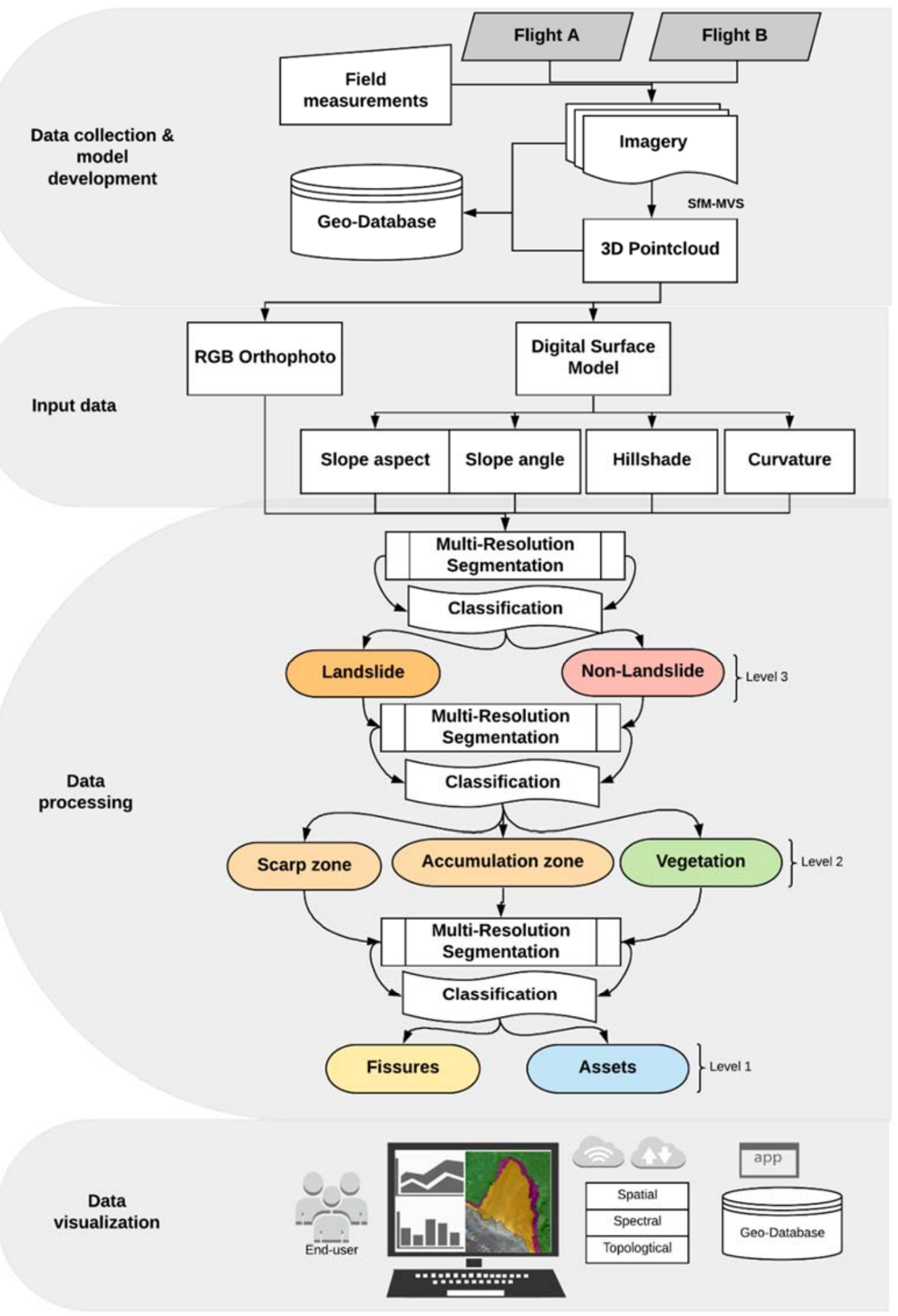

Figure 4. Workflow of the proposed methodology. 
The conceptualization of the current methodology has been built up on the basis of human cognition and how professional experts perceive landslide recognition and its morphodynamics. Based on the existing knowledge, specific features exist that usually are precursor signs of landslide activity and they present distinct zones for further investigation. Such typical topographic features could be the scarp and deposition zone, main and minor fissures or cracks, ridges, alterations of the drainage system [59]. The area affected by a mass movement usually has higher surface roughness than the surrounding stable terrain and the deposition zone has a convex profile shape. In addition, the scarp zone is usually steep (i.e., sharp-steep areas located close to very flat ones, significant changes in slope, etc.) and concave in shape with its main direction-flow being the same as the respective aspect. Scarps are significant features that form hazardous parts of landslides and their respective runout zones. On the contrary, concerning the non-landslide zone, the upper healthy part indicates higher elevation than the affected part, while the downslope is less clear with higher dissimilarity values due to the physical processes of landslide failure. The procedure is built on cognitive perception, which starts from scratch level of pre-field work and remote analysis, in situ experiments and data collection, specific landslide feature detection, OBIA modelling and detailed feature analysis and the final outcome of a characterization scheme with the respective statistics.

\subsection{Pre-Processing}

The initial phase includes the mission planning and execution, followed by 3D point cloud and relative products (orthophotos, DSM) creation and refinement. The latter supplies data for the object-based analysis phase. For each of the case sites, a semi-automated object-based characterization algorithm has been developed to detect and characterize landslide and non-landslide objects. From the orthophoto the mean values of red-green-blue (RGB) spectral indices have been used as individual spectral layers. In addition, four thematic datasets were created from the DSM data as input auxiliary layers in order to define the landslide hazard features: Hillshade, Curvature (profile), Slope Angle and Aspect. The final spatial level of detection (LoD) based on our data process was $0.5 \mathrm{~m}$. LoD is the smallest entity that can feasibly be identified using the proposed method. As a result, all the features with dimensions larger than the LoD are recognizable and valid.

\subsection{OBIA for Landslide Assessment}

This section presents the proposed object-based approach for the detailed characterization of the landslide site exploiting the semantic relationships among the landslide objects as it is defined by Varnes categorization [60]. The integrated mapping of landslide elements necessitates segmenting continuous topographical surface information into discrete, morphologically representative objects. We used OBIA to semi-automatically extract the landslide hazard areas. The overall framework included a multiresolution segmentation (MLS) with an expert rule-based (RB) feature extraction and classification at the object level based on deep learning. In the first step, multiple layers were fused, in order to be split into smaller regions and form the object primitives. The latter are used as entities for further classification.

Usually spectral information is employed to segment an image scene in a pixel-based approach. In the current study, spectral information is fused with auxiliary data resulted from the DSM to represent the 2.5D morphometric features information in order to use advanced objects' variables as classifiers on later stage. Orthomosaic (spectral information) and digital surface model (elevation information) plus four thematic layers (Slope angle and aspect, Curvature and Hillshade) (Figure 5) were partitioned into image objects using the cognition network language $(\mathrm{CNL})$ programming language incorporated in the eCognition ${ }^{\circledR}$ Developer 9.0 software package (Munich, Germany) [61]. Generation of image objects was achieved through an image segmentation procedure in eCognition ${ }^{\circledR}$ termed multiresolution segmentation (MLS). Multiresolution segmentation partitions an image into homogeneous multi-pixel regions based on several user-defined parameters. The latter is extensively used in landslide studies as best-fitted segmentation algorithm [62-64]. The user can influence the output of the segmentation 
process through specification and weighting of input data and definition of parameters affecting the size, spectral homogeneity, spatial homogeneity, and shape of the resulting image objects. The MLS segmentation algorithm is described as a region-merging procedure in which individual pixels are merged into primitives, followed by successive iterations in which small objects are incrementally merged into larger ones in such a way that heterogeneity of the image objects is eliminated. The merging process continues until a threshold derived from the user-defined parameters is reached [65]. Subsequently, the proper choice of segmentation scale is a tricky task for an accurate and optimal classification stage and most of the times, this is site dependent. Dragut presented the ESP tool and recently its updated version, which builds on the idea of local variance of object heterogeneity. In the current study, the ESP2-tool has been applied and delivered three statistically representative segmentation levels that have been evaluated through visual interpretation by multiple experts. At the same time trial and error segmentations showed that the different levels created during ESP2 were very close to the ones resulting from visual tests. As a result of an appropriate segmentation approach, three levels (40-80-160) of segmentation scales were defined. At the same time, shape factor and compactness factor remained constant at 0.4 and 0.5 respectively, for all the levels of information as they have been defined as the most representative values to represent landslide objects.

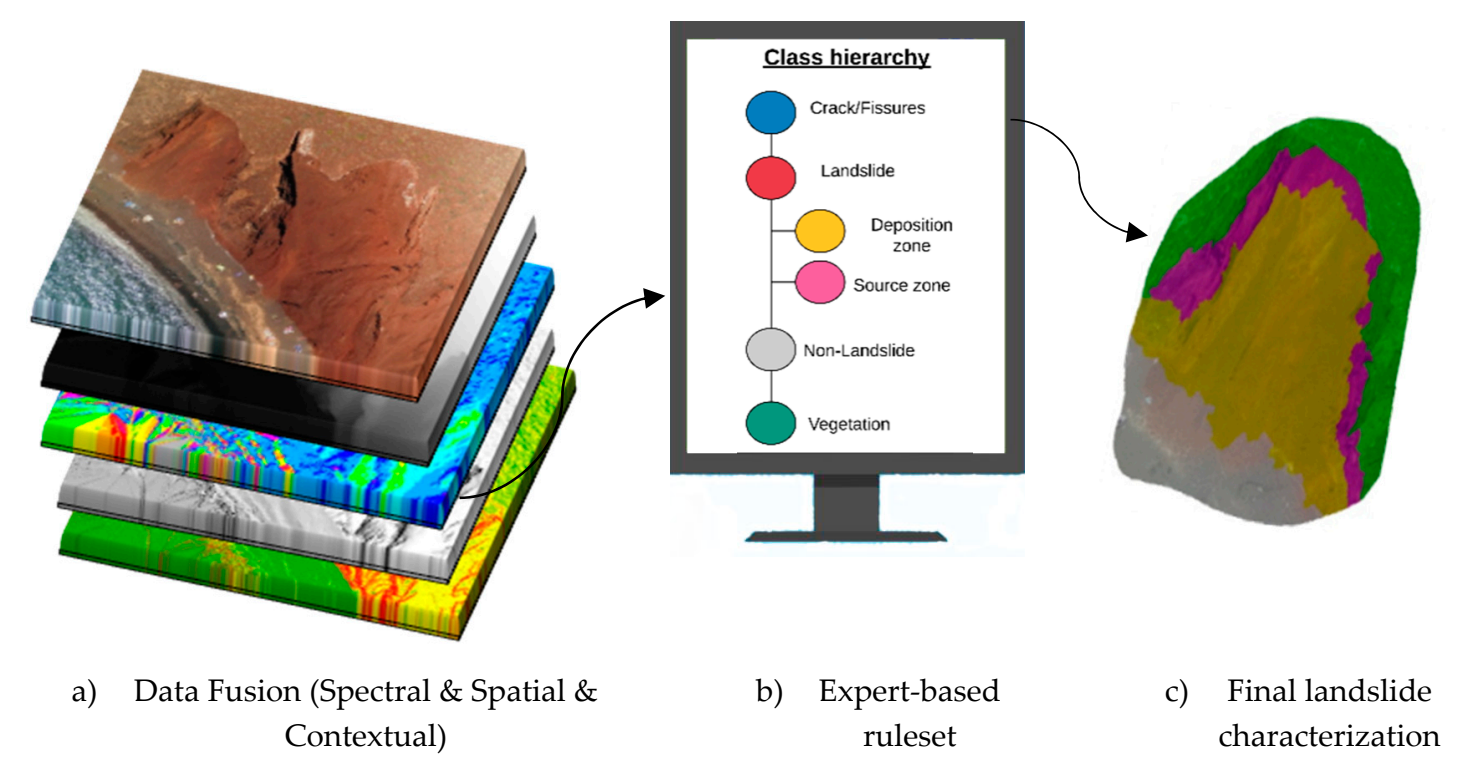

Figure 5. Conceptualization of proposed object-based image analysis (OBIA) flowchart. (a) Multiple layers fused for the segmentation procedure, (b) expert based OBIA ruleset, (c) final landslide characterization output.

The second phase includes the precise RB classification of the resulted segments into landslide hazard categories according to several spectral, textural and morphometric parameters (Table 2). Rule-based classification basically means combining the optimal features of different data sources (RGB, DSM, etc.) to extract specific classes based on the case under investigation and the desired task by using certain rules to regulate the different attributes. An exploratory analysis of the image segments' properties determined the selection of thresholds. Two initial classes at the Level-3 were defined which represents the basic (coarser) level: (a) Landslide and (b) Non-Landslide with further Level-2 «child» classification in $\left(\mathrm{a}_{\mathrm{i}}\right)$ Landslide--Source area, $\left(\mathrm{a}_{\mathrm{ii}}\right)$ Landslide--Deposition area and $\left(\mathrm{b}_{\mathrm{i}}\right)$ Non-Landslide-Vegetation. In a different level of hierarchy (Level-1) but at the same time connected with the above levels (Landslide--Non-Landslide), cracks and fissures were identified as engineering geological information concerning the landslide hazard. Finally, the derived classes of OBIA phase were validated against a reference inventory from the investigated sites. Statistics were applied to assess their respective accuracy and precision of classification process. Excess green index [66] has 
been used for vegetation identification in our test sites which constitutes one of the most widely used indices in the visual spectrum.

Table 2. Attributes used in the study for landslide object-based detection and characterization.

\begin{tabular}{|c|c|c|c|}
\hline \multicolumn{4}{|c|}{ Parameterization } \\
\hline Attribute & Information & Purpose & Landslide conception \\
\hline \multicolumn{4}{|c|}{ Spectral attributes } \\
\hline $\begin{array}{l}\text { Layer (min, max, } \\
\text { average, Standard } \\
\text { deviation) }\end{array}$ & $\begin{array}{l}\text { The value of pixels comprising the region } \\
\text { in band Red, Green, Blue }\end{array}$ & Classifier & $\begin{array}{l}\text { Colour values used to distinguish } \\
\text { eroded surfaces or specific class } \\
\text { discrimination due to their individual } \\
\text { spectral signatures }\end{array}$ \\
\hline Brightness & $\begin{array}{l}\text { The value is defined as the mean of all } \\
\text { spectral bands. }\end{array}$ & Classifier & $\begin{array}{l}\text { High brightness values in landslide } \\
\text { affected areas, due to loss of vegetation } \\
\text { and exposure of the rockmass }\end{array}$ \\
\hline $\begin{array}{l}\text { EGI (Excessive } \\
\text { Greenness Index) }\end{array}$ & Vegetation index, EGI $=(2 \times g-r-b)[66]$ & Classifier & $\begin{array}{l}\text { Spectral index used for vegetation } \\
\text { classification }\end{array}$ \\
\hline \multicolumn{4}{|c|}{ Spatial attributes } \\
\hline Convexity & $\begin{array}{l}\text { Measures the object's convexity } \\
\text { or concavity. }\end{array}$ & Classifier & $\begin{array}{l}\text { Scarp/Source zone: concave } \\
\text { Downslope are mostly convex }\end{array}$ \\
\hline Roundness & $\begin{array}{l}\text { Measure that compares the area of the } \\
\text { object to the square of the maximum } \\
\text { diameter of the object. }\end{array}$ & $\begin{array}{l}\text { Classifier - } \\
\text { Refinement }\end{array}$ & $\begin{array}{l}\text { Deposition zones are presented as } \\
\text { round shaped areas of } \\
\text { accumulated material }\end{array}$ \\
\hline Area & $\begin{array}{c}\text { Total area of the objects, minus the area of } \\
\text { the holes. }\end{array}$ & $\begin{array}{l}\text { Classifier - } \\
\text { Refinement }\end{array}$ & $\begin{array}{l}\text { Refinement of different classes based on } \\
\text { their coverage }\end{array}$ \\
\hline Main direction & Direction across the main polyline. & Classifier & $\begin{array}{l}\text { Deposition: Diffused direction } \\
\text { Scarp: main direction-flow in relation } \\
\text { with aspect }\end{array}$ \\
\hline Length/Width & $\begin{array}{l}\text { The length of an object divided by } \\
\text { its width. }\end{array}$ & Classifier & $\begin{array}{l}\text { Cracking features present elongated } \\
\text { features with high values of } \mathrm{L} / \mathrm{W}\end{array}$ \\
\hline Lineness & $\begin{array}{l}\text { Skeleton polylines which serve as surface } \\
\text { discontinuities. }\end{array}$ & Classifier & $\begin{array}{c}\text { Crack/fissure identification based on } \\
\text { skeleton polylines }\end{array}$ \\
\hline \multicolumn{4}{|c|}{ Texture attributes } \\
\hline $\begin{array}{c}\text { GLCM } \\
\text { Homogeneity }\end{array}$ & $\begin{array}{l}\text { GLCM is a tabulation of how often } \\
\text { different combinations of pixel brightness } \\
\text { values (gray levels) occur. } \\
\text { Image homogeneity, the value is high if } \\
\text { GLCM is concentrated along the diagonal. }\end{array}$ & Classifier & $\begin{array}{l}\text { Higher values at the failure material } \\
\text { (Landslide zones) than stable terrain } \\
\text { (Non landslide) }\end{array}$ \\
\hline $\begin{array}{c}\text { GLCM } \\
\text { Dissimilarity }\end{array}$ & $\begin{array}{l}\text { Texture measurement of the amount of } \\
\text { local variation. It increases linearly and is } \\
\text { high if the object has a high contrast. }\end{array}$ & Classifier & $\begin{array}{l}\text { Higher values at the failure material } \\
\text { (Landslide zones) than stable terrain } \\
\text { (Non landslide) }\end{array}$ \\
\hline \multicolumn{4}{|c|}{ Topological attributes } \\
\hline $\begin{array}{l}\text { Mean diff to } \\
\text { neighbors }\end{array}$ & $\begin{array}{l}\text { For each neighboring object, the layer } \\
\text { mean difference is computed and } \\
\text { weighted with regard to the length of the } \\
\text { border between the objects. }\end{array}$ & Refinement & $\begin{array}{c}\text { Topological rules applied for classes } \\
\text { refinement }\end{array}$ \\
\hline Relative border to & $\begin{array}{l}\text { Object's common border percentage with } \\
\text { neighboring ones. }\end{array}$ & Refinement & $\begin{array}{l}\text { Topological rules applied for classes } \\
\text { refinement }\end{array}$ \\
\hline Elevation & $\begin{array}{l}\text { Location of sharp-steep areas close to very } \\
\text { flat ones. }\end{array}$ & Classifier & $\begin{array}{l}\text { Stable part has higher elevation than } \\
\text { landslide zone }\end{array}$ \\
\hline Slope & Gradient: $0-90^{\circ}$, significant slope change. & Classifier & $\begin{array}{l}\text { Scarp: Steep with its main } \\
\text { direction-flow in relation with aspect } \\
\text { Stable zones: Low values, } \\
\text { small variations }\end{array}$ \\
\hline
\end{tabular}


Moreover, for the discontinuity surface detection, researchers [67] developed a semi-automated top-down object-based methodology for extracting lineaments from airborne magnetic data. In the current study, the aforementioned algorithm has been used for crack and fissure identification. The so-called object-based lineament detection (OBLD) line extraction algorithm used the line extraction tool in CNL language to produce a 'lineness' raster from the data used in the segmentation phase. In the current study, the resulted lines have been imposed a detailed refinement to reduce potential noise such as shadows and misalignments. The result has been vectorized into skeleton polylines with the respective object's properties which serve as surface discontinuities (crack and/or fissure) after the classification.

\subsection{Accuracy Assessment}

The proposed methodology and results were examined in order to assess their efficiency and quality in properly detecting and classify objects. In the current study the validation procedure has been done in two distinct steps. Initially, a qualitative validation was applied by visual interpretation of the achieved classes; the second step was to assess the OBIA classification against a reference inventory of the wide area in order to quantify the spatial agreement of the compared datasets. As well mentioned in [34], the term "agreement" instead of "accuracy" is better fitted in landslide mapping procedures. Two types of error can be found in the validation procedure: the omission errors which represent areas where the reference suggests a landslide that is not present in the OBIA classification result and the commission errors occurring in areas where the OBIA classification suggests a landslide that is not present in the reference. Finally, user's accuracy value expresses the correctly classified area as a share of the classification area that includes errors of commission.

\section{Analysis and Results}

For the landslide sites, the developed characterization algorithms followed similar pattern (uniform classifiers used), but segmentation classification rules had to be adapted to each individual case site. The object-based approach includes two main steps which interlink with each other: (i) the segmentation of the fused datasets, and (ii) scene classification on the developed knowledge-based ruleset. The initial phase encompasses the determination of appropriate input layers for segmentation, determination of the optimum parameters for the MLS. The second phase entails the appropriate extraction of "landslide hazardous regions" and "non-landslide" information with the optimal image object metrics in order to be used for further landslide risk management procedures.

\subsection{Data Analysis}

Regarding the segmentation stage, the ESP tool has been used to estimate the local variances along the generated objects from the multiresolution segmentation. The latter serve to identify the topographical variations to determine whether the object boundaries represent distinct morphological features in agreement with the natural process under this study. Three different segmentation parameters were selected and represent the three intercorrelated levels of the objects' hierarchy with L1 to be the finest level, L2 to be the moderate level and L3 the coarser level. Regarding the compactness factor, it has been kept at 0.5 for the three levels and for the shape factor was set at 0.4 respectively. In detail, Landslide--Non-Landslide category (L3) represents the parental category, whilst L2 category represents the object levels such as scarp, deposition and vegetation and L1 category represents cracks/fissures and assets such as road, coastline etc. Both L2 and L1 correlate as "child" levels of L3 and in the same way L1 has a "child" relationship with L2. Based on the segmentation result and the object creation, the following step was to provide a knowledge-based ruleset of the selected categories on each respective level. The appropriate selection of samples has been constructed either based on the field work experience mostly and visual assessment. In order to assess the metrics to be used for each category a quality assessment has been provided for best-fit class attribute for each case site (Figure 6). The latter has aided the proper classifier choice as best class descriptor. It was decided that if a classifier 
rate was above 0.51 confidence level, it should then be used in the detection phase. In the current study, the evaluation of the image object metrics for Red Beach and Proussos sites revealed that the EGI index used for detecting the vegetated areas was an effective metric for excluding vegetated areas (unaffected zone) from landslide ones. Meanwhile, for crack and fissure identification the "lineness" layer played a vital role in successfully identifying morphological discontinuities in both cases. Slope information was crucial for landslide recognition and the related categories of scarp and deposition areas and excluding unwanted flat areas (road network, assets). In the end, a significant refinement of the related objects has been taken with the neighborhood relation between classes in order to optimize the class borders.

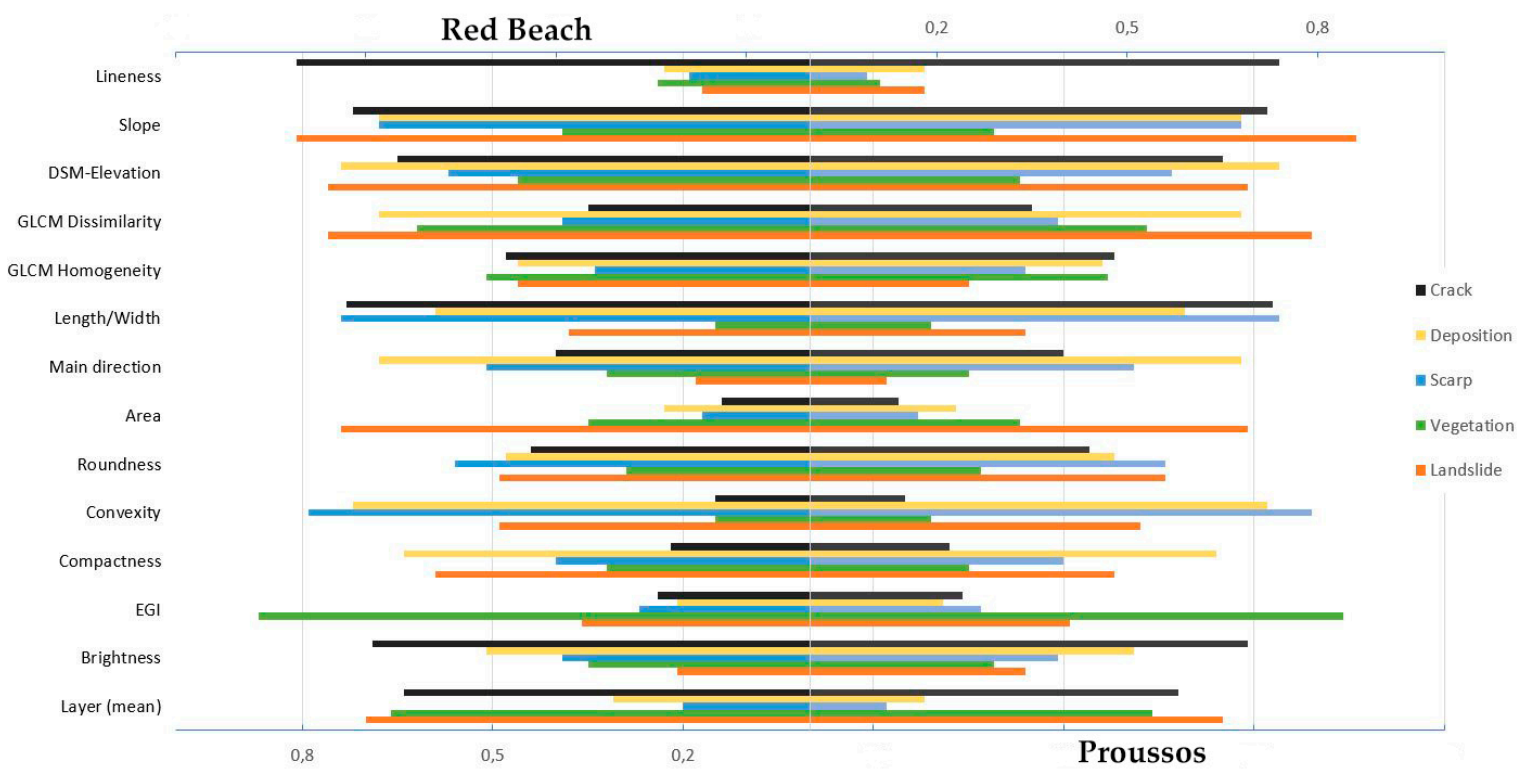

Figure 6. Quality assessment of classifiers used in the expert-ruleset for object characterization for Red Beach and Proussos case sites.

\subsubsection{Red Beach Site, Santorini}

The specific area of Red Beach suffers from multiple failure zones due to erosion induced by wave action and the low tensile strength of the scoria formation which result in deconfinement of the rock masses and the formation of extensive tension cracks. The toppling of rock blocks due to vertical tensile and multiple joints represents the main mechanism of failure in combination with planar sliding of well-cemented scoria along the upper parts of the red cliffs since the planes of the volcanic material daylight with regard to the slope face and present low strength along them. Moreover, small to medium sized volcanic bombs are present due to differential erosion and wave undermining. Consequently, geological and structural conditions are playing a vital role in transforming those slopes in landslide prone areas. Three landslide areas have been revealed from the proposed methodology in Red Beach site, namely Zone 1, Zone 2 and Zone 3 (Figure 7, Table 3). For each landslide zone the identical OBIA procedure has been followed. The maximum widths of the source and deposition areas are $35 \mathrm{~m}$ and $50 \mathrm{~m}$, respectively. The average dip angle is $41^{\circ}$ and the main sliding direction is $\mathrm{N} 78^{\circ}$. The projected area of the landslide zones is approximately $37,355 \mathrm{~m}^{2}$, the maximum sliding distance is $30 \mathrm{~m}$, and the height is about $55 \mathrm{~m}$. 


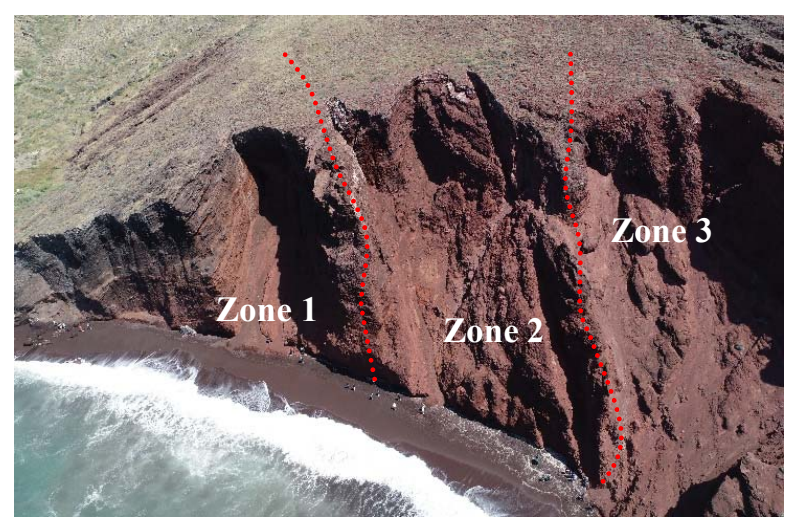

Figure 7. Aerial view from Red Beach site with the distinct landslide zones separated from red dashed line.

Table 3. Segmentation and classification parameters.

\begin{tabular}{ccc}
\hline \multicolumn{2}{c}{ Segmentation Parameters } & Classification Parameters \\
\hline & & Lineness, \\
L1 & Scale: 40 & Brightness, \\
& Shape: 0.4 & Slope, \\
& Compactness: 0.5 & Lineness \\
\hline L2 & Scale: 80 & RGB, GLCM, \\
& Shape: 0.4 & Convexity, \\
& Compactness: 0.5 & Roundness, Length-width \\
\hline \multirow{2}{*}{ L3 } & Scale: 160 & Slope, \\
& Shape: 0.4 & EGI, \\
& Compactness: 0.5 & Direction \\
\hline
\end{tabular}

For the segmentation stage three different scale values have been used based on the respective level of information. For L3 a scale factor of 160 has been chosen to fulfil the basic level of information (Landslide vs. Non-Landslide). For L2 a scale factor of 80 has been chosen to represent the «child» classes of Landslide (Scarp, Deposition) and Non-Landslide (Vegetation). In the finest level, L1 the lowest scale factor has been chosen (40) in order to detect the minor and major cracks of the landslide site and exclude unwanted information. In the initial classification step, test site's segments have been classified as landslide or non-landslide objects, according to the Level 3 segmentation. In the second step, a new level (Level-2) was created and directly linked with the super objects (Landslide-Non-landslide) with categories such as vegetation for Non-landslide (super-object) and scarp and depositional sediments for Landslide (super-object) category. In the most detailed assessment, (Level-1) categories such as coastline and physical assets for Non-landslide and cracks and fissures for both main categories have been identified based on numerous parameters. In the current study site, there are vegetated regions which due to its low heights, have similar reflectance and geometric properties as the landslide category. These areas were classified as landslides in the first classification step and refined later as vegetation. Vegetation refinement has been based on local roughness low values in combination with EGI in order to recognize unaffected area with vegetation. Figure 8 presents the specific levels of OBIA procedure regarding the case site in Red Beach. The respective parametric and non-parametric attributes have been extracted and stored in a geodatabase, since the initial classification level. For the derived crack/fissure objects along with their information such as width, length and main direction they have been exported as specific layer but at the same time linked with interrelationships with the super categories (Landslide--Non-Landslide). 

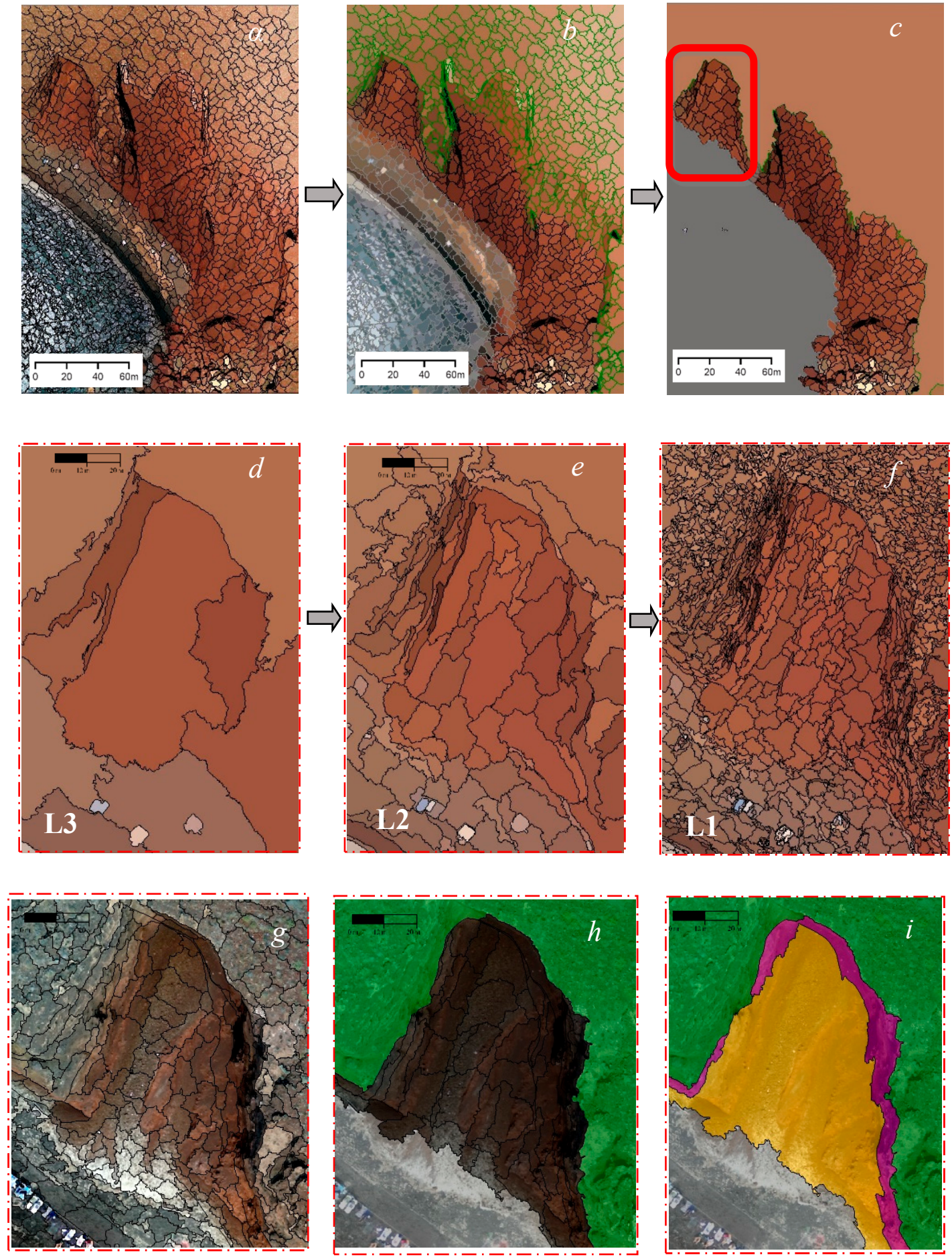

Figure 8. Red Beach object-based detection results. (a) Initial segmentation, (b) Detection of Vegetated areas and Non-Landslide candidates, (c) Identification of Landslide candidates and Non-Landslide has been excluded for next step, (d) L3 segmentation zone 1, (e) L2 segmentation zone 1, (f) L1 segmentation zone 1, (g) Initial segmentation zone 1, (h) Identification of Non-Landslide candidates (vegetation \& assets) zone 1, (i) Identification and final classification of Landslide and Non-Landslide classes zone 1 (Purple: scarp zone, Yellow: deposition zone, Green: Vegetation, Grey: Coastline (Asset)).

\subsubsection{Proussos Site, Evritania}

The Proussos slide (Figure 9, Table 4) has a narrow-inclined scarp and narrow lower portion as accumulated deposits. The main difference is that the current mass movements are behaving as a 
rockfall mechanism with specific planar slides along the bedding planes but at the same time providing large number of rockfall events due to toppling, after the intense folding along the height of the slope.

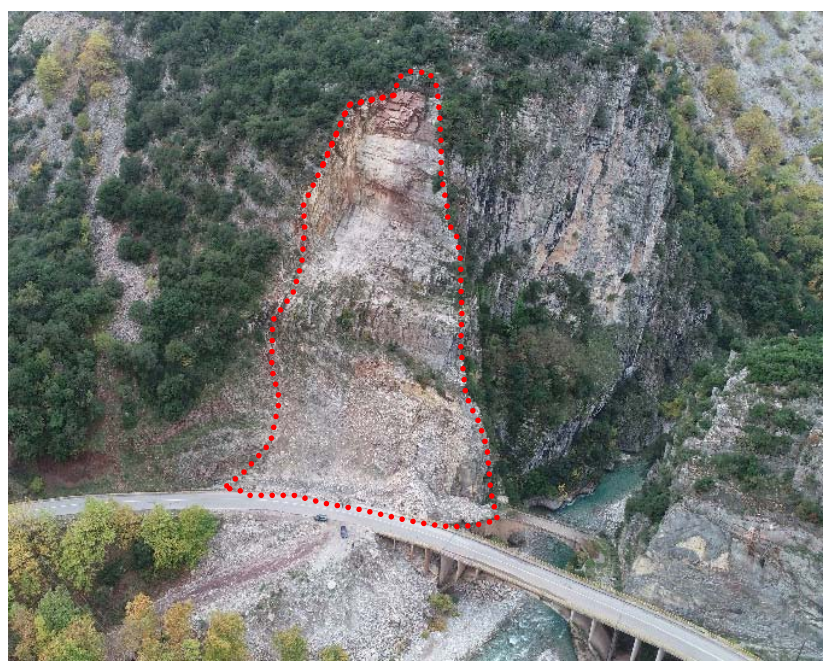

Figure 9. Aerial view from Proussos landslide site. Failure area is outlined with dashed red line.

Table 4. Segmentation and classification parameters.

\begin{tabular}{|c|c|c|}
\hline \multicolumn{2}{|c|}{ Segmentation Parameters } & Classification Parameters \\
\hline L1 & $\begin{array}{c}\text { Scale: } 40 \\
\text { Shape: } 0.4 \\
\text { Compactness: } 0.5\end{array}$ & $\begin{array}{l}\text { Lineness, } \\
\text { Brightness, } \\
\text { Slope, } \\
\text { Elevation, } \\
\text { Lineness }\end{array}$ \\
\hline L2 & $\begin{array}{c}\text { Scale: } 80 \\
\text { Shape: } 0.4 \\
\text { Compactness: } 0.5\end{array}$ & $\begin{array}{c}\text { RGB, GLCM, } \\
\text { Convexity, } \\
\text { Roundness, Length-width }\end{array}$ \\
\hline L3 & $\begin{array}{c}\text { Scale: } 160 \\
\text { Shape: } 0.4 \\
\text { Compactness: } 0.5\end{array}$ & $\begin{array}{c}\text { Slope, } \\
\text { EGI, } \\
\text { Direction }\end{array}$ \\
\hline
\end{tabular}

Due to intense tectonic activity in the wide region the specific case site is showing its tectonism with tilted rockmass formation and bedding range around $60^{\circ}$ on site. The scarp has been subject to continuous retrogressive erosion, as a result, its failure mechanism is behaving as a complex case with planar slides and rockfalls of diverse magnitudes. The maximum widths of the source and deposition zones are $26 \mathrm{~m}$ and $119 \mathrm{~m}$, respectively. The average dip angle is $60^{\circ}$ and the main sliding direction is $70^{\circ}$. The projected area of the entire landslide is $24,872 \mathrm{~m}^{2}$, the maximum sliding distance is $85 \mathrm{~m}$, and the height is about $100 \mathrm{~m}$ from 0 to $95 \mathrm{~m}$. As in the previous case, in the first classification step, the application site was classified as landslide and non-landslide objects according to the Level 1 segmentation. The second phase (Level-2) coincides the discrimination of the landslide category to subclasses of scarp and deposition zones while for the Non-Landslide category the vegetation had to be identified and excluded from the hazard assessment. Cracks/fissures and multiple assets such as the road network have been identified at the sub level (Level-3) (Figure 10). 

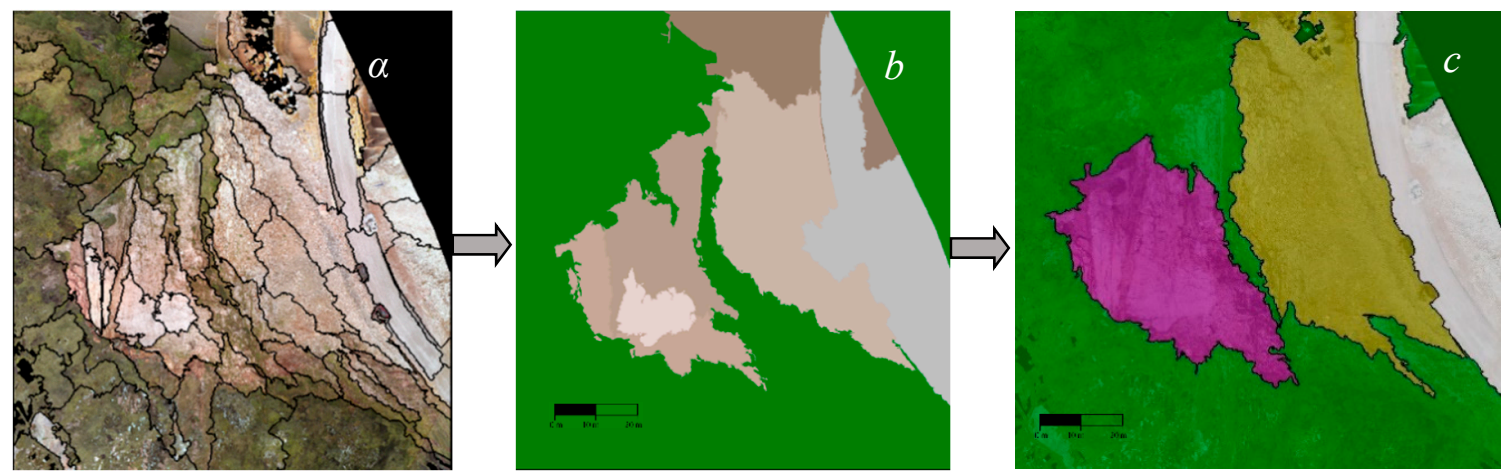

Figure 10. Proussos object-based detection results. (a) Level_1 Segmentation, (b) Detection of Vegetated areas and Non-Landslide candidates, (c) Identification and classification of Landslide and Non-Landslide classes (Purple: scarp zone, Yellow: deposition zone, Green: Vegetation, Grey: Road network (Asset)).

\subsection{Validation}

The validation procedure was carried out with two different approaches, firstly in a qualitative visual assessment and afterwards in a quantitative way based on spatial logic operations. Due to a priori knowledge of the areas under investigation we provided a stratified random sampling with representative samples for the quality control. The classification accuracy has been evaluated using reference data created by experts from visual interpretation of aerial photographs, orthoimages and satellite imagery as well as intense field work. It has been used to determine whether the percentage of test data is correctly classified or misclassified in specific predefined classes. It should be mentioned that conventional methods and expert delineation cannot be significantly more accurate than a semi-automated OBIA mapping result in local scale since the same reference dataset is used for mapping. A region-based approach has been processed to calculate the metrics which have been used for the completeness and correctness assessment via a code-script robustly concerning a buffer zone of one pixel. The aim of both procedures was to compare the area between the extracted objects from OBIA against the reference data (Table 5).

Table 5. Accuracy metrics for the two landslide case sites under investigation.

\begin{tabular}{ccccc}
\hline \multirow{2}{*}{ Metrics } & \multicolumn{2}{c}{ Red Beach } & \multicolumn{2}{c}{ Proussos } \\
\cline { 2 - 5 } & Scarp & Deposition & Scarp & Deposition \\
\hline Object-based image analysis & 277.75 & 457.26 & 1045.51 & 2198.47 \\
classification $\left(\mathrm{m}^{2}\right)$ & 91.52 & 428.58 & 764.27 & 1286.59 \\
Expert classification $\left(\mathrm{m}^{2}\right)$ & +186.23 & +28.68 & +281.24 & +911.88 \\
Difference $\left(\mathrm{m}^{2}\right)$ & 74 & 83 & 79 & 86 \\
Overlap $(\%)$ & 78.1 & 80.8 & 81.4 & 80.2 \\
Producer's accuracy (\%) & 75.6 & 77.4 & 80.3 & 77.9 \\
User's accuracy (\%) & 21.9 & 19.2 & 18.6 & 19.8 \\
Omission error (\%) & 24.4 & 22.6 & 19.7 & 22.1 \\
Commission error $(\%)$ & & & & \\
\hline
\end{tabular}

Producer accuracy [68] is defined as the probability of a specific value in a given class will be classified correctly. On the contrary, user accuracy [68] is defined as the probability that a value predicted to be in a certain class is certainly in. The latter is based on the fraction of correctly predicted values to the total number of values predicted to be in a specific class. Errors of omission refer to reference datasets which have been left out (or omitted) from the correct class in the OBIA classification stage. 
On the contrary, errors of commission refer to misclassifications included in one category which is being evaluated. In the site of Red Beach, based on the reference dataset, an overestimation of the scarp and deposition zones has been outlined from the developed model. OBIA model regarding the scarp zone, estimated almost one third of the reference dataset. The Proussos site constitutes a more complex landslide case with multiple failure mechanisms (planar, toppling) in the same case, due to intense local tectonism and weathering. The latter was an overburden that the model had to cope with. As a result, model prediction has been underestimated by almost $325 \mathrm{~m}^{2}$ for scarp zone. Same trend was followed for the deposition zone with a difference of $178 \mathrm{~m}^{2}$.

\section{Discussion}

Both landslide sites have a presented common trend in the classification scheme which indicates that the methodological concept is relatively constant and quite objective for the extraction of landslide classes under similar conditions. In both cases extraction of over $83 \%$ of landslide deposition zones was observed, indicating the successful applicability of the semi-automated OBIA conceptualization that is presented in this research. On the contrary, the producer's accuracy for scarp/source zones in both cases was less than $80 \%$, due to a relatively high number of false negatives. This is because of the fuzziness of the natural processes' boundaries in the real world. For example, there is great uncertainty of the differentiations caused by intermediary transitivity between depositional and scarp zones. Therefore, it leads to a misclassification of features in the vicinity of the scarp segments which decrease the accurate separation of landslide classes. The latter indicates that the current approach tends to underestimate the scarp/source class compared with the deposition one. It should be mentioned that scarp zone in Red Beach has been under-classified due to the fact that its boundaries were not so clear as quite extensive shadowing was observed caused by its steepness $\left(80-90^{\circ}\right)$. The shadowing can create serious misclassifications in relative studies as in many remote sensing applications. Thus, sun orientation should be taken into consideration during the data collection stage in order to exclude as much as possible, shadowed areas caused by topography. Excessive green index has been found ideal for vegetation identification and it could serve as an alternative solution when the NIR band is not available. In addition, Red Beach deposition zones have been under-classified with the red zone not even being classified accordingly as deposit zone (Figure 11). A remarkable difference has been noticed in Proussos case where OBIA classification identified almost two times the expert mapping extent of the deposition zone. The latter is a result of the subjectivity which lies on understanding the actual deposit boundaries which present great fuzziness due to the continuous evolution of natural processes.

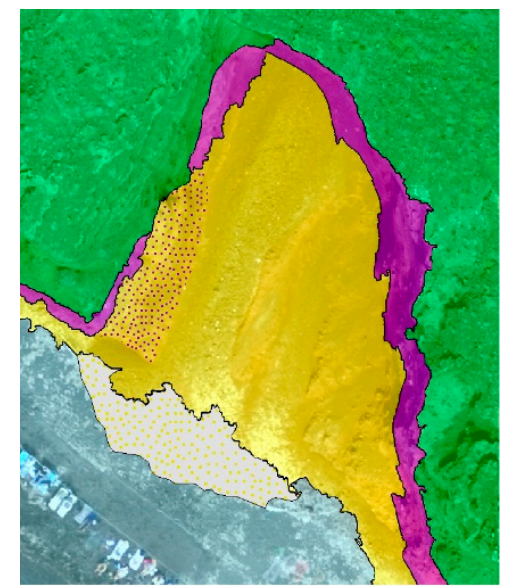

Figure 11. Misclassification errors occurred in the Red Beach case site. Purple dots are representing areas of scarp while they have been misclassified as deposits. On the contrary, yellow dots on grey background represent areas of deposit zone while they have been misclassified as assets. 
One of the identified limitations for the current method lies in the fact that expert mapping does not provide sufficient and coherent validation for local scale mass movement events due to biased exports and, most of the times, the subjectivity towards expert's perception. In addition, we should indicate that deposit class in the current study represents areas of accumulated sediments and rockfall materials resulted from mass movement processes, weathering and erosion. The aforementioned material, in case of Red Beach, has been wiped out almost instantly due to coastal dynamics while in the Proussos case, local authorities have cleared the road network in order to be functionable straight after the event. As a result, the OBIA "depletion zone" class includes a large part of the washed bedrock layer. Consequently, for deeper understanding of the failure mechanism, field investigations and in situ studies are mandatory procedures. The latter becomes more crucial when engineering geological investigations are needed in order to comprehend the sliding surface with kinematic analysis when multiple failures surfaces and mechanisms are impacting in the area under investigation. In this context, the authors are continuously working to cover the precise identification of different kind of mass movement mechanisms (rockfall, rotational, translational) and incorporate engineering geological assessments with computer vision and OBIA techniques.

\section{Conclusions}

During the last decade, UAVs and computer vision have enabled landslide studies to introduce new ways of data representation. Specifically, real-time application, in combination with the elimination of human risk constitute the UAVs as highly effective and efficient tools for data collection in terms of cost and extent. New methodologies in remote sensing are leading to incorporating artificial intelligence and deep learning on ultra-high spatial resolution datasets to classify a scene according to human perception, closing the gap between machines and humans. Furthermore, the use of UAV platforms presents a significant advance in the field of landslide and rockfall management. In mountainous environments, field investigation for landslide detection and characterizations can be challenging. In this context, the results illustrate that detection of landslide hazard zones from ultra-high-resolution imagery for capacity management can be performed with relatively high accuracy in a semi-automated sense and at the same time, cost-effectively. The proposed OBIA semi-automated landslide mapping procedure developed within the scope of the study, resulted in a most realistic scheme for natural process detection and characterization compared with pixel-based methods. It should be mentioned that landslide elements that do not present sufficient topographic signatures can cause misclassification errors in OBIA procedure. Such a homogenization by means of spectral, spatial, and topological information accompanied by the monitoring of the evolution of areas of specific homogeneity degree (i.e., scarp, deposition zone, etc.) at different stages of the landslide process may be eventually used as a guide toward the establishment of solid and quantitative definitions of those landslide elements.

The current study has introduced a novel semi-automated approach for the detailed detection and characterization of landslide elements from UAV ultra high-resolution products. The aim of this work was to indicate the use of UAV photogrammetric techniques combined with object-based approaches to derive a more informative analysis of "real" landslide features. Moreover, systematic identification using OBIA tracking of displacements may be helpful in cases of detailed semantic labelling of landslide information in order to propose detailed remedial and protection measures in site-specific scenarios. Our results have demonstrated that the use of ultra high-resolution overlapping imagery can be adopted as an effective tool for landslide mapping and identification in site-specific scales, while the challenges it poses will be tackled in future authors' work. Also, a significant challenge was to test the effectiveness of collecting accurate measurements against any critical issues such as bad weather conditions, occlusions, and exposure issues. As in many cases of landslide prone areas around the world, the occurrence of local events without any post assessment report is frequent. Following the proposed study, a cost-effective and efficient solution could be adapted for local authorities in order to enhance mass movement capacity and preparedness. 
Author Contributions: Conceptualization, E.K.; Data curation, E.K.; Formal analysis, E.K.; Funding acquisition, E.K. and V.M.; Investigation, E.K.; Methodology, E.K.; Project administration, E.K.; Resources, E.K.; Software, E.K.; Supervision, V.M., E.V. and B.C.; Validation, E.K.; Visualization, E.K.; Writing-original draft, E.K.; Writing-review \& editing, E.K., V.M. and E.V. All authors have read and agreed to the published version of the manuscript.

Funding: This research is co-financed by Greece and the European Union (European Social Fund- ESF) through the Operational Programme «Human Resources Development, Education and Lifelong Learning» in the context of the project "Strengthening Human Resources Research Potential via Doctorate Research" (MIS-5000432), implemented by the State Scholarships Foundation (IK $\Upsilon$ ).

Acknowledgments: The authors deeply thank the three anonymous reviewers and the Editors for their time and effort dedicated to providing their valuable feedback and their insightful comments which are greatly appreciated.

Conflicts of Interest: The authors declare no conflicts of interest.

\section{References}

1. Jaedicke, C.; Van Den Eeckhaut, M.; Nadim, F.; Hervás, J.; Kalsnes, B.; Vangelsten, B.V.; Smith, J.T.; Tofani, V.; Ciurean, R.; Winter, M.G.; et al. Identification of landslide hazard and risk "hotspots" in Europe. Bull. Eng. Geol. Environ. 2014, 73, 325-339. [CrossRef]

2. Vassilakis, E.; Foumelis, M.; Erkeki, A.; Kotsi, E.; Parcharidis, I.; Lekkas, E. Multitemporal Surface Deformation Analysis of Amyntaio Slide (Greece) Using Remotely Piloted Airborne System and Structure-from-Motion photogrammetry; National and Kapodistrian University of Athens: Athens, Greece, 2019.

3. Valkaniotis, S.; Papathanassiou, G.; Ganas, A. Mapping an earthquake-induced landslide based on UAV imagery; case study of the 2015 Okeanos landslide, Lefkada, Greece. Eng. Geol. 2018, 245, 141-152. [CrossRef]

4. Guzzetti, F.; Mondini, A.C.; Cardinali, M.; Fiorucci, F.; Santangelo, M.; Chang, K.-T. Landslide inventory maps: New tools for an old problem. Earth-Sci. Rev. 2012, 112, 42-66. [CrossRef]

5. Giordan, D.; Hayakawa, Y.; Nex, F.; Remondino, F.; Tarolli, P. Review article: The use of remotely piloted aircraft systems (RPASs) for natural hazards monitoring and management. Nat. Hazards Earth Syst. Sci. 2018, 18, 1079-1096. [CrossRef]

6. Corominas, J.; van Westen, C.; Frattini, P.; Cascini, L.; Malet, J.-P.; Fotopoulou, S.; Catani, F.; Van Den Eeckhaut, M.; Mavrouli, O.; Agliardi, F.; et al. Recommendations for the quantitative analysis of landslide risk. Bull. Eng. Geol. Environ. 2014, 73, 209-263. [CrossRef]

7. Lahousse, T.; Chang, K.T.; Lin, Y.H. Landslide mapping with multi-scale object-based image analysis-A case study in the Baichi watershed, Taiwan. Nat. Hazards Earth Syst. Sci. 2011, 11, 2715-2726. [CrossRef]

8. Van Westen, C.J.; van Asch, T.W.J.; Soeters, R. Landslide hazard and risk zonation-Why is it still so difficult? Bull. Eng. Geol. Environ. 2006, 65, 167-184. [CrossRef]

9. Corominas, J.; Moya, J. A review of assessing landslide frequency for hazard zoning purposes. Eng. Geol. 2008, 102, 193-213. [CrossRef]

10. Casagli, N.; Cigna, F.; Bianchini, S.; Hölbling, D.; Füreder, P.; Righini, G.; Del Conte, S.; Friedl, B.; Schneiderbauer, S.; Iasio, C.; et al. Landslide mapping and monitoring by using radar and optical remote sensing: Examples from the EC-FP7 project SAFER. Remote Sens. Appl. Soc. Environ. 2016, 4, 92-108. [CrossRef]

11. Scaioni, M.; Longoni, L.; Melillo, V.; Papini, M. Remote sensing for landslide investigations: An overview of recent achievements and perspectives. Remote Sens. 2014, 6, 9600-9652. [CrossRef]

12. Zhao, C.; Lu, Z. Remote sensing of landslides-A review. Remote Sens. 2018, 10, 279. [CrossRef]

13. Borghuis, A.M.; Chang, K.; Lee, H.Y. Comparison between automated and manual mapping of typhoon-triggered landslides from SPOT-5 imagery. Int. J. Remote Sens. 2007, 28, 1843-1856. [CrossRef]

14. Joyce, K.; Samsonov, S.; Jolly, G. Satellite remote sensing of volcanic activity in New Zealand. In Proceedings of the 2008 Second Workshop on Use of Remote Sensing Techniques for Monitoring Volcanoes and Seismogenic Areas, Napoli, Italy, 11-14 November 2008; pp. 1-4.

15. Blaschke, T.; Hay, G.J.; Kelly, M.; Lang, S.; Hofmann, P.; Addink, E.; Queiroz Feitosa, R.; van der Meer, F.; van der Werff, H.; van Coillie, F.; et al. Geographic object-based image analysis-Towards a new paradigm. ISPRS J. Photogramm. Remote Sens. 2014, 87, 180-191. [CrossRef] [PubMed] 
16. Hossain, M.D.; Chen, D. Segmentation for Object-Based Image Analysis (OBIA): A review of algorithms and challenges from remote sensing perspective. ISPRS J. Photogramm. Remote Sens. 2019, 150, 115-134. [CrossRef]

17. Moosavi, V.; Talebi, A.; Shirmohammadi, B. Producing a landslide inventory map using pixel-based and object-oriented approaches optimized by Taguchi method. Geomorphology 2014, 204, 646-656. [CrossRef]

18. Chen, Y.; Su, W.; Li, J.; Sun, Z. Hierarchical object oriented classification using very high resolution imagery and LIDAR data over urban areas. Adv. Space Res. 2009, 43, 1101-1110. [CrossRef]

19. Hamedianfar, A.; Shafri, H.Z.M.; Mansor, S.; Ahmad, N. Improving detailed rule-based feature extraction of urban areas from WorldView-2 image and lidar data. Int. J. Remote Sens. 2014, 35, 1876-1899. [CrossRef]

20. Berhane, T.; Lane, C.; Wu, Q.; Anenkhonov, O.; Chepinoga, V.; Autrey, B.; Liu, H. Comparing pixel- and object-based approaches in effectively classifying wetland-dominated landscapes. Remote Sens. 2017, 10, 46. [CrossRef]

21. Keyport, R.N.; Oommen, T.; Martha, T.R.; Sajinkumar, K.S.; Gierke, J.S. A comparative analysis of pixel- and object-based detection of landslides from very high-resolution images. Int. J. Appl. Earth Obs. Geoinf. 2018, 64, 1-11. [CrossRef]

22. Shackelford, A.K.; Davis, C.H. A combined fuzzy pixel-based and object-based approach for classification of high-resolution multispectral data over urban areas. IEEE Trans. Geosci. Remote Sens. 2003, 41, 2354-2364. [CrossRef]

23. Lizarazo, I.; Elsner, P. Segmentation of remotely sensed imagery: Moving from sharp objects to fuzzy regions. In Image Segmentation; Ho, P.-G., Ed.; InTechOpen: London, UK, 2011; ISBN 978-953-307-228-9.

24. Drăguţ, L.; Csillik, O.; Eisank, C.; Tiede, D. Automated parameterisation for multi-scale image segmentation on multiple layers. ISPRS J. Photogramm. Remote Sens. 2014, 88, 119-127. [CrossRef]

25. Mohan Vamsee, A.; Kamala, P.; Martha, T.R.; Vinod Kumar, K.; Jai Sankar, G.; Amminedu, E. A tool assessing optimal multi-scale image segmentation. J. Indian Soc. Remote Sens. 2018, 46, 31-41. [CrossRef]

26. Dou, J.; Chang, K.-T.; Chen, S.; Yunus, A.; Liu, J.-K.; Xia, H.; Zhu, Z. Automatic case-based reasoning approach for landslide detection: Integration of object-oriented image analysis and a genetic algorithm. Remote Sens. 2015, 7, 4318-4342. [CrossRef]

27. Martha, T.R.; Kerle, N.; van Westen, C.J.; Jetten, V.; Kumar, K.V. Segment optimization and data-driven thresholding for knowledge-based landslide detection by object-based image analysis. IEEE Trans. Geosci. Remote Sens. 2011, 49, 4928-4943. [CrossRef]

28. Stumpf, A.; Kerle, N. Object-oriented mapping of landslides using Random Forests. Remote Sens. Environ. 2011, 115, 2564-2577. [CrossRef]

29. Chen, T.; Trinder, J.; Niu, R. Object-oriented landslide mapping using ZY-3 satellite imagery, random forest and mathematical morphology, for the Three-Gorges Reservoir, China. Remote Sens. 2017, 9, 333. [CrossRef]

30. Liu, T.; Abd-Elrahman, A.; Morton, J.; Wilhelm, V.L. Comparing fully convolutional networks, random forest, support vector machine, and patch-based deep convolutional neural networks for object-based wetland mapping using images from small unmanned aircraft system. GISci. Remote Sens. 2018, 55, 243-264. [CrossRef]

31. Mezaal, M.R.; Pradhan, B.; Sameen, M.I.; Mohd Shafri, H.Z.; Yusoff, Z.M. Optimized neural architecture for automatic landslide detection from high-resolution airborne laser scanning data. Appl. Sci. 2017, 7, 730. [CrossRef]

32. Karantanellis, E.; Marinos, V.; Vassilakis, E. 3D hazard analysis and object-based characterization of landslide motion mechanism using UAV imagery. ISPRS-Int. Arch. Photogramm. Remote Sens. Spat. Inf. Sci. 2019, 425-430. [CrossRef]

33. Blaschke, T. Object based image analysis for remote sensing. ISPRS J. Photogramm. Remote Sens. 2010, 65, 2-16. [CrossRef]

34. Hölbling, D.; Eisank, C.; Albrecht, F.; Vecchiotti, F.; Friedl, B.; Weinke, E.; Kociu, A. Comparing manual and semi-automated landslide mapping based on optical satellite images from different sensors. Geosciences 2017, 7, 37. [CrossRef]

35. Mayr, A.; Rutzinger, M.; Bremer, M.; Oude Elberink, S.; Stumpf, F.; Geitner, C. Object-based classification of terrestrial laser scanning point clouds for landslide monitoring. Photogramm. Rec. 2017, 32, 377-397. [CrossRef] 
36. Farmakis, I.; Marinos, V.; Papathanassiou, G.; Karantanellis, E. Automated 3D jointed rock mass structural analysis and characterization using LiDAR terrestrial laser scanner for rockfall susceptibility assessment: Perissa area case (Santorini). Geotech. Geol. Eng. 2020. [CrossRef]

37. Nex, F.; Remondino, F. UAV for 3D mapping applications: A review. Appl. Geomat. 2014, 6, 1-15. [CrossRef]

38. Peppa, M.V.; Mills, J.P.; Moore, P.; Miller, P.E.; Chambers, J.E. Brief communication: Landslide motion from cross correlation of UAV-derived morphological attributes. Nat. Hazards Earth Syst. Sci. 2017, 17, 2143-2150. [CrossRef]

39. Eisenbeiß, H. UAV Photogrammetry; Mitteilungen/Institut für Geodäsie und Photogrammetrie an der Eidgenössischen Technischen Hochschule Zürich; ETH, Inst. für Geodäsie und Photogrammetrie: Zürich, Switzerland, 2009; ISBN 978-3-906467-86-3.

40. Tziavou, O.; Pytharouli, S.; Souter, J. Unmanned Aerial Vehicle (UAV) based mapping in engineering geological surveys: Considerations for optimum results. Eng. Geol. 2018, 232, 12-21. [CrossRef]

41. Lucieer, A.; Jong, S.M.d.; Turner, D. Mapping landslide displacements using Structure from Motion (SfM) and image correlation of multi-temporal UAV photography. Prog. Phys. Geogr. Earth Environ. 2014, 38, 97-116. [CrossRef]

42. Colomina, I.; Molina, P. Unmanned aerial systems for photogrammetry and remote sensing: A review. ISPRS J. Photogramm. Remote Sens. 2014, 92, 79-97. [CrossRef]

43. Bendea, H.; Boccardo, P.; Dequal, S.; Tonolo, F.G.; Marenchino, D.; Piras, M. Low cost UAV for post-disaster assessment. In Proceedings of the XXIst ISPRS Congress: International Society for Photogrammetry and Remote Sensing, Beijing, China, 3-11 July 2008; pp. 1373-1380.

44. Tahar, K.N.; Ahmad, A.; Papamichail, D.; Ploussi, A.; Muniraj, I.; Guo, C.; Sheridan, J.T.; Liba, N. International Conference on Recent Trends in Physics 2016 (ICRTP2016). J. Phys. Conf. Ser. 2016, 755, 011001. [CrossRef]

45. Turner, D.; Lucieer, A.; de Jong, S. Time series analysis of landslide dynamics using an Unmanned Aerial Vehicle (UAV). Remote Sens. 2015, 7, 1736-1757. [CrossRef]

46. Vasuki, Y.; Holden, E.-J.; Kovesi, P.; Micklethwaite, S. Semi-automatic mapping of geological Structures using UAV-based photogrammetric data: An image analysis approach. Comput. Geosci. 2014, 69, 22-32. [CrossRef]

47. Niethammer, U.; Rothmund, S.; James, M.R.; Travelletti, J.; Joswig, M. Nav-based remote sensing of landslides. Int. Arch. Photogramm. Remote Sens. Spat. Inf. Sci.-ISPRS Arch. 2010, 38, 496-501.

48. D'Oleire-Oltmanns, S.; Marzolff, I.; Peter, K.D.; Ries, J.B. Unmanned aerial vehicle (UAV) for monitoring soil erosion in Morocco. Remote Sens. 2012, 4, 3390-3416. [CrossRef]

49. Murphy, R.R.; Duncan, B.A.; Collins, T.; Kendrick, J.; Lohman, P.; Sanborn, F. Use of a small unmanned aerial system for the SR-530 Mudslide Incident near Oso, Washington. J. Field Robot. 2016, 33, 476-488. [CrossRef]

50. Rau, J.Y.; Jhan, J.P.; Lo, C.F.; Lin, Y.S. Landslide mapping using imagery acquired by a fixed-wing Uav. ISPRS-Int. Arch. Photogramm. Remote Sens. Spat. Inf. Sci. 2012, 195-200. [CrossRef]

51. Sui, L.; Wang, X.; Zhao, D.; Qu, J. Application of 3D laser scanner for monitoring of landslide hazards. Int. Arch. Photogramm. Remote Sens. Spat. Inf. Sci. 2008, XXXVII, 277-282.

52. Koma, Z.; Székely, B.; Dorninger, P.; Rasztovits, S.; Roncat, A. Comparison of UAV and TLS DTMs for acquisition of geological, geomorphological information for Doren landslide. In Proceedings of the European Geosciences Union General Assembly 2014, Vienna, Austria, 27 April-2 May 2014; Volume 16.

53. Remondino, F.; Spera, M.G.; Nocerino, E.; Menna, F.; Nex, F. State of the art in high density image matching. Photogramm. Rec. 2014, 29, 144-166. [CrossRef]

54. Antonopoulos, J. The great Minoan eruption of Thera volcano and the ensuing tsunami in the Greek Archipelago. Nat. Hazards 1992, 5, 153-168. [CrossRef]

55. Antoniou, A.A.; Lekkas, E. Rockfall susceptibility map for Athinios port, Santorini Island, Greece. Geomorphology 2010, 118, 152-166. [CrossRef]

56. Marinos, V.; Prountzopoulos, G.; Asteriou, P.; Papathanassiou, G.; Kaklis, T.; Pantazis, G.; Lambrou, E.; Grendas, N.; Karantanellis, E.; Pavlides, S.; et al. Beyond the boundaries of feasible engineering geological solutions: Stability considerations of the spectacular Red Beach cliffs on Santorini Island, Greece. Environ. Earth Sci. 2017, 76, 513. [CrossRef]

57. Lindner, G.; Schraml, K.; Mansberger, R.; Hübl, J. UAV monitoring and documentation of a large landslide. Appl. Geomat. 2016, 8, 1-11. [CrossRef]

58. Pix4D. Pix4D www.pix4d.com, S.A.; Pix4D: Lausanne, Switzerland, 2019. 
59. Hungr, O.; Leroueil, S.; Picarelli, L. The Varnes classification of landslide types, an update. Landslides 2014, 11, 167-194. [CrossRef]

60. Cruden, D.; Varnes, D. Landslides: Investigation and Mitigation; Turner, A.K., Schuster, R.L., Eds.; Special Report/Transportation Research Board, National Research Council; National Academy Press: Washington, DC, USA, 1996; ISBN 978-0-309-06208-4.

61. eCognition Developer; Trimble: Sunnyvale, CA, USA, 2019.

62. Eisank, C.; Smith, M.; Hillier, J. Assessment of multiresolution segmentation for delimiting drumlins in digital elevation models. Geomorphology 2014, 214, 452-464. [CrossRef] [PubMed]

63. Hölbling, D.; Friedl, B.; Eisank, C. An object-based approach for semi-automated landslide change detection and attribution of changes to landslide classes in northern Taiwan. Earth Sci. Inform. 2015, 8, 327-335. [CrossRef]

64. Comert, R.; Avdan, U.; Gorum, T. Rapid mapping of forested landslide from ultra-high resolution unmanned aerial vehicle data. ISPRS-Int. Arch. Photogramm. Remote Sens. Spat. Inf. Sci. 2018,171-176. [CrossRef]

65. Baatz, M.; Schape, A. Multi resolution Segmentation: An optimum approach for high quality multi scale image segmentation. Proc. Angew. Geogr. Inf. 2000, XII, 12-23.

66. Woebbecke, D.M.; Meyer, G.E.; von Bargen, K.; Mortensen, D.A. Color indices for weed identification under various soil, residue, and lighting conditions. Trans. ASAE 1995, 38, 259-269. [CrossRef]

67. Middleton, M.; Schnur, T.; Sorjonen-Ward, P. Geological lineament interpretation using the Object-based Image Analysis approach: Results of semi-automated analyses versus visual interpretation. Geol. Surv. Finl. 2015, 57, 135-154.

68. Story, M.; Congalton, R. Accuracy assessment: A user's perspective. Am. Soc. Photogramm. Remote Sens. 1986, 52, 397-399.

(C) 2020 by the authors. Licensee MDPI, Basel, Switzerland. This article is an open access article distributed under the terms and conditions of the Creative Commons Attribution (CC BY) license (http://creativecommons.org/licenses/by/4.0/). 